\title{
Standard versus patient-centred asthma education in the emergency department: a randomised study
}

\author{
S. Smith*, C. Mitchell ${ }^{\#, *}$ and S. Bowler
}

ABSTRACT: High re-attendance rates are common after asthma emergency department (ED) care. Inadequate patient education has been cited as a potential cause of re-attendance and the optimal format of education is uncertain. The present study aimed to compare the effectiveness of patient-centred education (PCE) and standard asthma patient education on ED re-attendance.

A randomised controlled trial was conducted at two inner-city Australian teaching hospitals' EDs, where patients received either standard patient education (SPE) or PCE. Both groups received a six-topic curriculum. However, PCE patients reordered the topics according to their own priority and thus controlled the order of education.

In total, 146 adult patients presenting to EDs with acute asthma were enrolled. After 4 months, ED re-attendance decreased from 22 to $12 \%$ in the PCE group and remained unchanged in the SPE group (between group odds ratio 0.4 , 95\% confidence interval $(0.2-1.1)$ ). In 78 patients discharged after ED care, the PCE group had fewer re-attendances after 4 and 12 months (0.3 $(0.1-0.9)$ and $0.3(0.1-0.8)$, respectively ). PCE patients with no general practitioner care in the preceding 7 days had fewer re-attendances after 4 and 12 months $(0.1(0.0-0.7)$ and $0.2(0.0-0.6)$, respectively). A trend of better asthma control was evident, with a reduction in activity limitation.

In conclusion, patient-centred education offers promise as a brief education process in the emergency department. However, a large multicentre trial of patient-centred education is required.

\section{KEYWORDS: Asthma, emergency department, patient education}

A sthma mortality has declined in recent years even though asthma morbidity continues to affect the quality of life of individuals with asthma $[1,2]$. This is evident from the number of people with asthma presenting to emergency departments (EDs) [3-5]. Asthma patients' re-attendance rates after receiving $\mathrm{ED}$ care can be as high as $17 \%[6,7]$.

Numerous studies have found that people with acute asthma receive care that is inconsistent with asthma management guidelines, including inadequate discharge planning and education [6, 8-14]. Some studies of patients with acute asthma have focused interventions on improving primary care follow-up via telephone reminders [15] and primary care-based education [16], which have shown very little or no improvement in patient behaviour or asthma outcomes.

Patient education has been described as an essential component of asthma management, with clinical guidelines providing the basis for both clinical management and education curricula [17]. Prevention of further episodes of acute asthma is a focus of patient education, although to what extent it is effective remains unclear. Delayed education has shown limited positive outcomes. A brief, opportune, educational intervention in the ED may be a useful adjunct to current ED care and would be consistent with international and national guidelines [2, 18]. However, asthma education studies poorly describe the teaching and learning principles underpinning the asthma education process [19].

Unlike previous studies, the current study sought to examine the process of educating patients through a focus on teaching and learning behaviour. The method used a learner-centred approach [20], as the concepts were congruent with the central tenets of patient-centred care [21]. Standard patient education (SPE) differs from a learner-centred approach as it usually starts with pathophysiology and ends with the

\section{AFFLLIATIONS}

${ }^{*}$ Centre for Evidence-Based Medicine, Dept of Primary Health Care, University of Oxford, Oxford, UK.

${ }^{\#}$ School of Medicine, University of Queensland, Herston,

"Dept of Respiratory Medicine,

Princess Alexandra Hospital,

Woolloongabba, and

${ }^{+}$Dept of Medicine, Mater Adult

Public Hospital, Raymond Terrace,

South Brisbane, Australia.

CORRESPONDENCE

S. Smith

University of Oxford

Centre for Evidence-Based Medicine Dept of Primary Health Care

Old Road Campus

Headington

Oxford

OX3 7LF

UK

Fax: 441865289336

E-mail: smithsm01@yahoo.com.au

Received:

May 032007

Accepted after revision:

January 062008

\section{SUPPORT STATEMENT}

This work received support from the Cooperative Research Centre (CRC) for Asthma and Asthma Australia, through a Health Education and Health Promotion Scholarship in 2001, and from an Asthma Foundation of Queensland grant in 2001-2002.

\section{STATEMENT OF INTEREST}

Statements of interest for S. Smith and S. Bowler can be found at www.erj.ersjournals.com/misc/ statements.shtml

Online ISSN 1399-3003 
importance of ongoing review [22, 23]. Standard education is often the way health professionals are educated. The present authors aimed to compare patient-centred education (PCE) with SPE, looking at the subsequent effects on the number of further ED attendances and asthma control. The same curriculum, based on a clinical guideline, was used for PCE and SPE.

\section{MATERIALS AND METHODS Study design}

The present study was a prospective randomised controlled trial of two methods of patient education for people with asthma attending an ED. PCE [19] was underpinned with learnercentred principles, while SPE represented the traditional method of patient education. The primary aim of PCE was a reduction in ED re-attendance rates after 4 and 12 months. The secondary aim was to improve asthma control. Asthma control was evidenced by the patient's symptoms and reliever medication use in the 7 days prior to the ED attendance and at an outpatient department (OPD) visit 4-6 weeks after initial presentation. Ethical clearance was obtained from participating hospitals (Princess Alexandra Hospital and Mater Adult Public Hospital, Brisbane, Australia) and the Queensland University of Technology (Brisbane, Australia) Ethics Committee.

\section{Study setting and population}

The present study was conducted at two large teaching hospitals in Brisbane, Australia, from August 2001 until August 2002. Adult patients arriving at the ED with an acute exacerbation of asthma were invited to participate after medical clearance was given by the attending physician.

To be eligible, patients had to have been diagnosed with asthma prior to this presentation, aged $>18$ yrs, able to read and write English and have no other concurrent respiratory medical condition. Patients were excluded from the study if deemed too ill to participate by the medical officer and/or required intensive care medical treatment. Case notes were used to confirm the participant's eligibility and to exclude patients with other respiratory diseases and conditions that cause dyspnoea.

\section{Study protocol}

The procedures involved in the concealed allocation of patients to the study are outlined in table 1 . Patients were medically managed prior to contact with the researcher. After giving their consent to the study, each of the 146 patients completed a questionnaire and placed it in a sealed envelope. Patients were randomised by their day of birth, with odd days receiving the intervention of PCE $(n=68)$ and even days being assigned to the control group of SPE $(n=78)$. The education was given to patients during their ED presentation. Staff at both EDs were blind to the randomisation process, as there was no notification of group assignment in the patient's chart. Only the researcher and the patient were present when the education was given.

\section{Intervention}

The asthma education protocol comprised a curriculum commonly used nationally and internationally [17, 22-24]. The curriculum for both groups was primarily based on a clinical guideline known as the Australian Six Step Asthma Management Plan (table 2).

The control group receiving SPE commenced with step 1 (asthma pathophysiology) and progressed sequentially through to step 6 (educate and review; table 2). The study intervention required the PCE participants to prioritise the six asthma curriculum steps according to their perceived need, and patients were educated accordingly so that the topic most important to them was covered first. The PCE process was underpinned by the self-determination theory, which emphasises autonomy, competence and relationship support. A review of this theory of human motivation in learner-centred education has been reported elsewhere [19, 20, 25]. The PCE intervention also required participants to respond to two openended questions: "What is the most important issue for you at the moment?" and "What is the most important asthma issue for you at the moment?"

Each education session took $\sim 20 \mathrm{~min}$ to complete. The PCE sessions lasted an additional $5-10 \mathrm{~min}$ as the educator addressed the patient's issues derived from the two openended questions. For both groups, an Asthma Foundation leaflet was given to patients to support the verbal advice of the educator and to take home for future reference. The leaflet conveyed similar information to the asthma education curriculum. One clinician (S. Smith) educated all the patients.

\section{Measurements}

Demographic, clinical and asthma control data were collected at the time of attending the ED (phase 1) and at the OPD follow-up appointment 4-6 weeks later (phase 2). Patients attending the follow-up OPD were subsequently educated again according to the ED randomisation. Participants' attendances at the ED in the 12 months prior to the asthma education intervention were recorded through self-report and secondary care audit data. Re-attendance information was collected through hospital records 4 and 12 months after phase 1 (fig. 1).

\section{TABLE 1 Procedures in concealed allocation of patients to education groups}

\section{Step Procedures}

$1 \quad$ Patient arrives at emergency department and is triaged, researcher is notified by phone of the potential participant and travels to hospital

2 Patient is medically managed, stabilised and their chart checked by medical staff; medical officer grants permission for researcher to see patient

3 Patient is given study information then invited to participate; consent form is signed, date of birth checked and questionnaire given to patient for completion

$4 \quad$ Patient educated after completion of questionnaire, patient's chart indicates asthma study without information on group assignment; outpatient appointment date and time given to patient and recorded in chart 


\begin{tabular}{lll} 
TABLE 2 & $\begin{array}{l}\text { The components of the asthma education curriculum as related to the six steps of the Australian Asthma Management } \\
\text { Plan (AAMP) }\end{array}$ & Asthma education curriculum \\
\hline Step & AAMP & What is asthma and how do I know I have it? \\
\hline $\mathbf{1}$ & Identification of the high-risk patient: assess severity & How to achieve my best lung function \\
$\mathbf{3}$ & Achieve best lung function & How to stay well and identify and avoid trigger factors \\
$\mathbf{4}$ & Maintain best lung function: avoid and identify trigger factors & How to stay well through my medications \\
$\mathbf{5}$ & Maintain best lung function: optimise medication programme & What is an action plan and how do I use it to help my asthma? \\
$\mathbf{6}$ & Develop an action plan & How often do I need to have education and see the doctor?
\end{tabular}

Asthma control was measured using the asthma control questionnaire (ACQ) by JUNIPER et al. [26]. This validated method records the symptoms from the previous 7 days, along with $\beta_{2}$-agonist use. Asthma control data were collected at the time of ED attendance and again 4-6 weeks later in the OPD. Participants completed the questionnaire independently. Patients were educated on completion of the questionnaire.

\section{Statistical analysis}

All analyses were hypothesis driven and the two primary outcomes of interest were ED re-attendances and asthma control. Paired t-tests, ANOVAs and ANCOVAs were used to compare means of data that were normally distributed. The

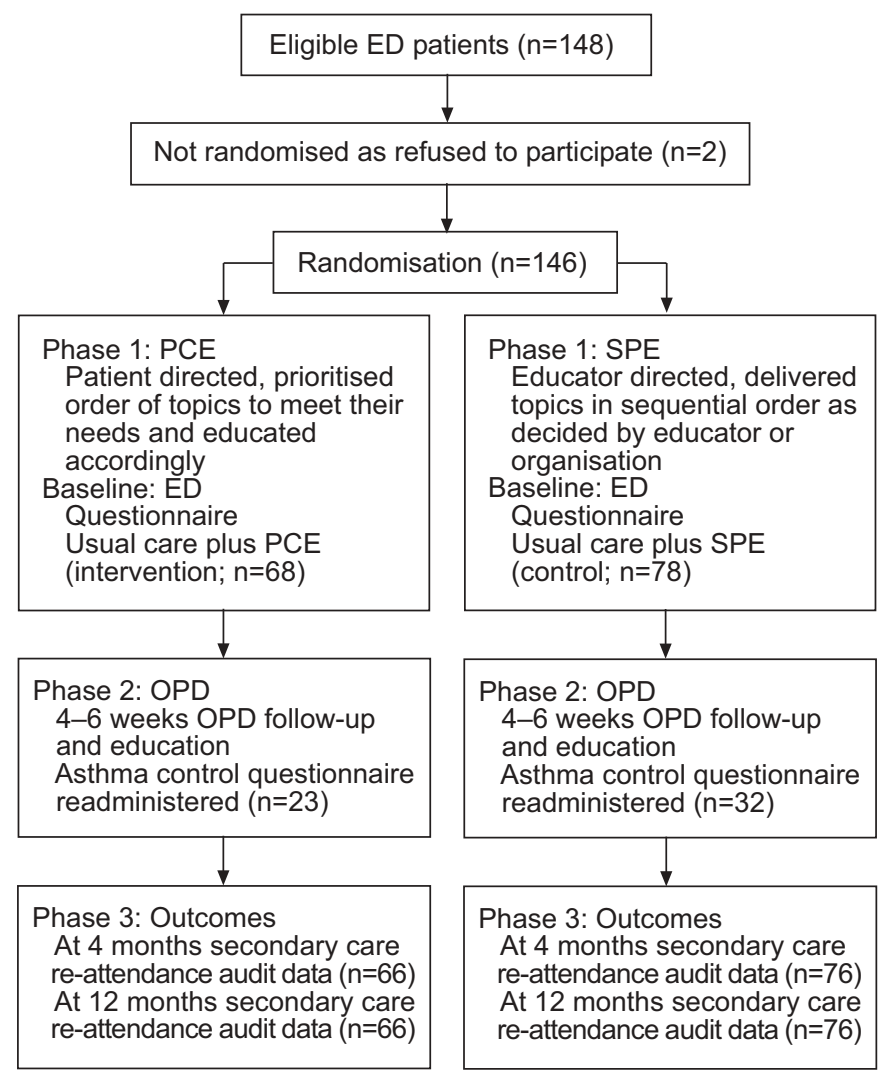

FIGURE 1. Summary of participant flow, numbers and timing of randomised assignment, interventions and data collection points. ED: emergency department; PCE: patient-centred education; SPE: standard patient education; OPD: outpatient department.
McNemar test was used for repeat measures of categorical data. In analyses of categorical data with small samples, statistical associations were assessed using the Fisher exact test. For previous admission and new admission data, the Wilcoxon test (nonparametric) was used to test the significance of differences between two related samples, while the Mann-Whitney U-test was used to test for differences between the control and intervention groups. Odds ratios (OR) were calculated, with 95\% confidence intervals (CI) being reported. Logistic regressions were undertaken to determine any difference between subgroups, such as those that did or did not attend a secondary care medical OPD follow-up appointment.

\section{RESULTS}

\section{Study population}

In total, 148 adults with acute asthma who sought ED care were invited to participate in the study (fig. 1). Only two potential participants declined. The mean age was consistent with other asthma studies [22, 23, 27].

However, the study cohort had higher levels of formal education and lower levels of income than other study cohorts; $49.2 \%$ had an income <AU $\$ 20,000$, while only $8 \%$ described themselves as unemployed. Despite the low income levels in comparison to the average Australian income (AU\$55,000), a quarter of the study population stated they had private health insurance. Before ED presentation, participants in both education groups had similar prior ED attendances (table 3 ).

\section{Topic prioritisation, patient and asthma issues}

Many of the patients in the PCE group chose a different order for the asthma education topics, compared with the standard curriculum (table $2 ; \mathrm{p} \leqslant 0.001$ ). At the time of phase 1 ED presentation, the PCE group's topic order followed a pattern of step numbers 3, 2, 4, 5, 6 and 1 . During the OPD phase of the study, the patients' prioritisation changed in order of importance to steps $4,3,2,5,6$ and 1 . Also, PCE responses to the two open-ended questions in the ED generated a number of patient and asthma issues. These responses differed slightly to those expressed a number of weeks later in the OPD (table 4).

\section{Primary outcome: re-attendance}

The SPE group had no reduction in ED re-attendance rate (23\%) 4 months after receiving education in the ED. In contrast, the PCE group had halved the frequency of re-attendance to $12 \%$. The between group comparison $(n=146)$ of these differences was not statistically significant (OR 0.4; 95\% CI (0.2-1.1)). However, when controlling for general practitioner 


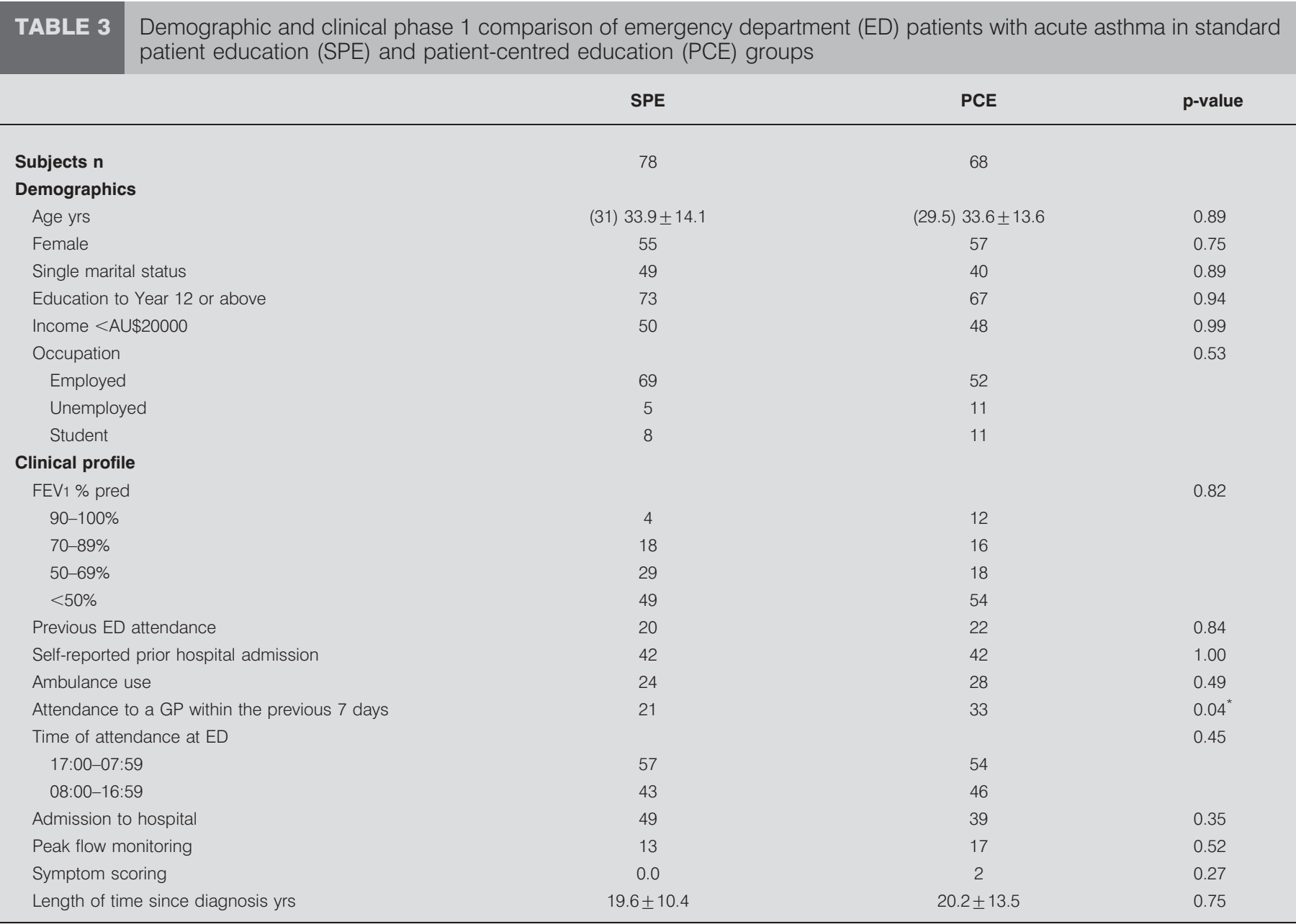

Data are presented as (median) mean \pm SD, \% or mean \pm SD, unless otherwise stated. FEV1: forced expiratory volume in one second; \% pred: \% predicted; GP: general practitioner. ${ }^{*}: p<0.05$, indicating significant difference between groups.

(GP) differences at baseline (phase 1), PCE patients had fewer re-attendances (F-statistic with one degree of freedom $\left(\mathrm{F}_{(1)}\right)$ $4.84, \mathrm{p}=0.03)$. In total, 104 patients had not seen their GP in the 7 days prior to seeking care at the ED. In this subgroup, those randomised to PCE had significantly fewer re-attendances than the standard group $(\mathrm{p}=0.01)$.

Re-attendance rates did not differ for the 55 patients who received additional education in the OPD at $4(\mathrm{p}=0.68)$ and
12 months $(\mathrm{p}=0.96)$. However, when follow-up secondary care and prior care by the GP was controlled for, the PCE patients had fewer re-attendances than the control group $\left(F_{(1)}\right.$ 5.0, $\mathrm{p}=0.03)$.

For 78 patients who were treated, educated and discharged from the ED (not admitted to a hospital ward), the PCE group had significantly fewer re-attendances at 4 and 12 months (OR $0.3,95 \%$ CI (0.1-0.9) and OR 0.3, 95\% CI (0.1-0.8), respectively;

TABLE 4 Most important patient and asthma issues from two open-ended questions, at the time of attending the emergency department (ED) and outpatient department (OPD) follow-up

ED

Employment issues

Financial pressures

Family responsibilities

Relationship issues

Most important asthma issues
Elimination of symptoms

Prevention

Controlling asthma

\section{OPD}

Staying healthy

Lifestyle issues

Education and employment obligations

Legal and financial concerns

Controlling asthma

Planning for future attacks

Side-effects of medications 
All patients

Patients not admitted to hospital ward Patients admitted to hospital ward

Not admitted to hospital ward, no prior GP care Not admitted to hospital ward, prior GP care Admitted to ward, no prior GP care

Admitted to ward, prior GP care

Patients with asthma for $>10$ yrs

Patients with asthma for $>10 \mathrm{yrs}$, not admitted to hospital ward

Patients with asthma for $>10 \mathrm{yrs}$, admitted to hospital ward

Patients with asthma for $>10$ yrs, no prior GP care Patients with asthma for $>10 \mathrm{yrs}$, prior GP care
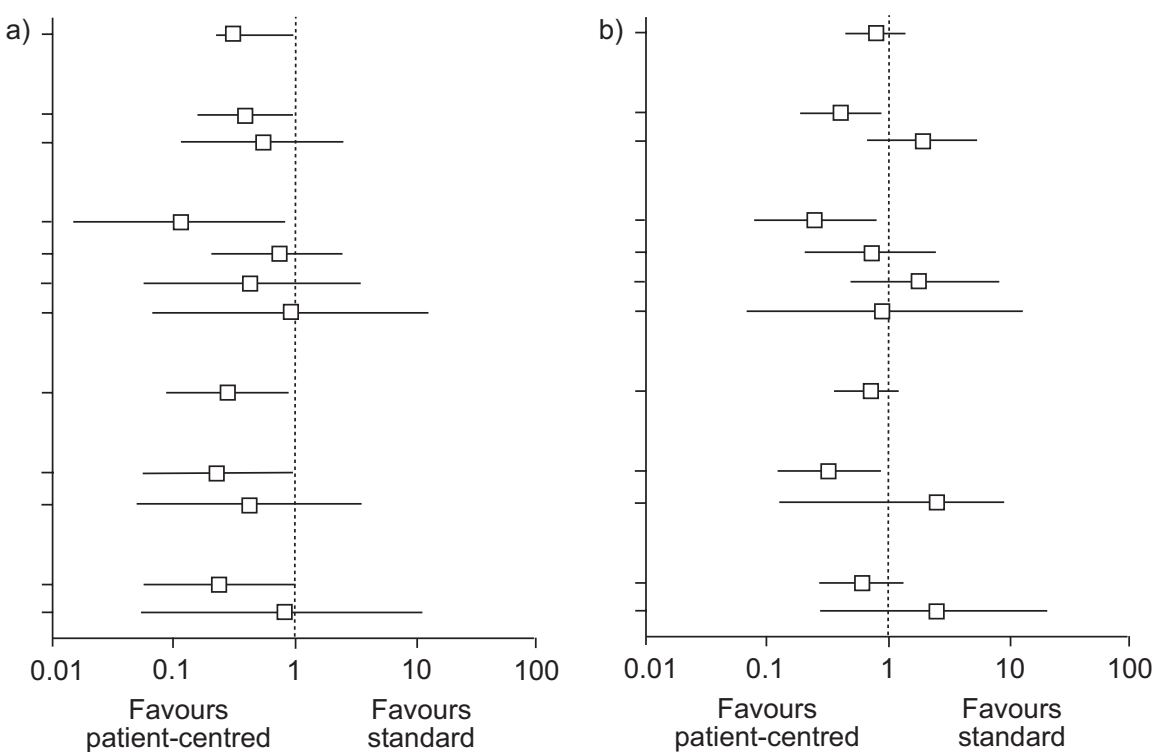

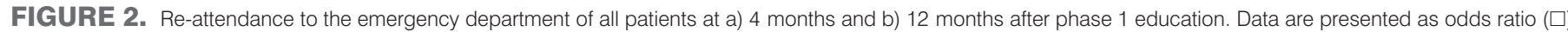
and $95 \%$ confidence interval (-). GP: general practitioner.

fig. 2). Furthermore, in this patient subgroup of those who also had not received recent GP care $(n=63)$, the PCE patients were less likely to re-attend (0.1 (0.0-0.7) and $0.2(0.0-0.6)$ after 4 and 12 months, respectively; fig. 2).

Additionally, people who had been diagnosed with asthma for $>10$ yrs also appeared to benefit from the PCE process. These patients had fewer ED visits within 4 months of being educated, although this was not sustained until 12 months (0.2 (0.1-0.9) and 0.3 (0.3-1.6), respectively; fig. 2).

In the present study, forced expiratory volume in one second (FEV1) values were utilised to assess levels of acute asthma severity. Asthma severity was not associated with having seen a GP in the 7 days prior to presenting to the ED $(\mathrm{p}=0.57)$ nor with hospital admission $(\mathrm{p}=0.14)$.

\section{Secondary outcome: asthma control}

Asthma control was reported in two formats: first with all seven questions of the ACQ (symptoms, $\beta_{2}$-agonist use and FEV1) and secondly with six questions pertaining to symptoms and $\beta_{2}$-agonist use (table 5).

Asthma control in all 55 patients improved between the ED (phase 1) and OPD follow-up (phase 2). However, when asthma control group differences at time of entry to the study were controlled for, a trend towards the PCE group gaining better control can be seen $\left(\mathrm{F}_{(1)} 2.13, \mathrm{p}=0.13\right)$. More specifically, the SPE group reported more activity limitation, with the PCE having a greater mean change difference that was significant between groups $(\mathrm{p}=0.03)$.

Overall, the mean difference between educational groups from phase 1 (ED) and phase 2 (OPD) confirms a trend of better asthma control for the PCE group (table 5). In the subgroup of 40 patients discharged from the ED, patients receiving the PCE intervention reported better asthma control (all criteria mean difference $-6.59,95 \%$ CI $(-13.90-0.70))$ and fewer symptoms (mean difference $-6.55,95 \%$ CI (-13.33-0.22)). The high number of patients that did not attend the OPD medical follow-up appointment meant that comparisons using asthma control as an outcome were limited. In an analysis that included only the 55 patients that had full follow-up, there was a nonsignificant positive effect of the PCE $(p=0.13)$. To carry out an intentionto-treat (ITT) analysis, asthma control was modelled using baseline demographic data (age, sex, occupation, education level and income level) and asthma control at ED presentation from patients with complete data. Missing values for asthma control at follow-up were imputed using this model; imputed and observed values were used in the ITT analysis, resulting in a nonsignificant positive effect of PCE $(p=0.31)$.

\section{Limitations}

Studies undertaken in the ED are inherently difficult, with competing priorities for patients and health professionals. To overcome this difficulty, one researcher educated all patients involved in the study, which introduced a potential bias. By using the same curriculum for both groups and the researcher ensuring, in the most part, that the same words were used for each topic, irrespective of the assigned education group, the potential bias was reduced. Asthma emergency presentations during the data collection period may have been affected due to unusually mild summer and winter seasons, which could have decreased the asthma control scores. More patients in the control SPE group than in the PCE group returned to the OPD and received education, which could have limited the impact of the PCE intervention in reducing re-attendances.

There was a potential for contamination in patients who were admitted to a hospital ward because asthma education forms usual in-patient care at both study hospitals. Although the

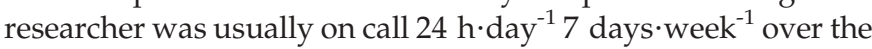
12-month study period, there were some days when the researcher was not available. On average, the researcher was off call for one weekend in three, during which time potential study participants were not given the opportunity to participate. 
TABLE 5 Asthma control questionnaire at phase 1 and phase 2

\begin{tabular}{|c|c|c|c|c|c|c|c|}
\hline & \multicolumn{3}{|c|}{ SPE } & \multicolumn{3}{|c|}{ PCE } & \multirow{2}{*}{$\begin{array}{c}\text { Mean change } \\
\text { difference between } \\
\text { groups p-value }\end{array}$} \\
\hline & $\begin{array}{c}\text { Phase } 1 \\
\text { ED }\end{array}$ & $\begin{array}{c}\text { Phase } 2 \\
\text { OPD }\end{array}$ & p-value & $\begin{array}{c}\text { Phase } 1 \\
\text { ED }\end{array}$ & $\begin{array}{c}\text { Phase } 2 \\
\text { OPD }\end{array}$ & $p$-value & \\
\hline \multicolumn{8}{|l|}{ Symptoms } \\
\hline All & $2.88 \pm 0.39$ & $1.37 \pm 0.43$ & $<0.01$ & $2.83 \pm 0.50$ & $1.12 \pm 0.48$ & $<0.01$ & 0.09 \\
\hline Activity limitation & $2.68 \pm 1.53(76)$ & $1.44 \pm 1.50(32)$ & 0.04 & $2.61 \pm 1.78(62)$ & $0.87 \pm 1.04(23)$ & $<0.01$ & $0.03^{*}$ \\
\hline Shortness of breath & $3.54 \pm 1.32(76)$ & $1.78 \pm 1.53(32)$ & $<0.01$ & $3.49 \pm 1.66(63)$ & $1.78 \pm 1.20(23)$ & $<0.01$ & 0.34 \\
\hline Wheeze & $2.64 \pm 1.26(76)$ & $1.25 \pm 1.04(32)$ & $<0.01$ & $2.32 \pm 1.38(63)$ & $0.91 \pm 0.84(23)$ & $<0.01$ & 0.39 \\
\hline$\beta_{2}$-agonist use & $3.54 \pm 1.78(74)$ & $2.06 \pm 1.69(31)$ & $<0.01$ & $3.10 \pm 1.91(60)$ & $1.57 \pm 1.08(23)$ & $<0.01$ & 0.35 \\
\hline FEV1 \% pred & $4.68 \pm 1.57(72)$ & $1.60 \pm 1.93(25)$ & $<0.01$ & $4.49 \pm 2.00(61)$ & $1.24 \pm 1.75(21)$ & $<0.01$ & 0.69 \\
\hline All criteria & $3.17 \pm 0.47$ & $1.49 \pm 0.56$ & $<0.01$ & $3.20 \pm 0.46$ & $1.21 \pm 0.52$ & $<0.01$ & 0.12 \\
\hline
\end{tabular}

A number of participants $(61.8 \% ; \mathrm{PCE}=66 \%$; $\mathrm{SPE}=58 \%)$ did not attend their OPD appointment despite utilisation of a number of reminder strategies previously reported to be successful [28]. These strategies included making the appointment at the time the patient presented to the ED and contacting the patient by telephone the night before their appointment. However, the present return rate to the OPD was consistent with other public hospital asthma studies [29, 30]. Analysis of data indicated no difference in demographic and clinical characteristics or prior care from a GP between patients that did or did not return for follow-up.

\section{DISCUSSION}

A systematic review of the limited asthma education for adults reports little benefit for the patient in "the way it is currently practised" and identifies a need for reconsideration [31]. In the present study, the traditional method of teaching patients was challenged through the application of a learner-centred process that shared common elements to patient-centred care [19]. The PCE also incorporated the acknowledgement of issues facing patients, in addition to their asthma, as the first step in building a therapeutic alliance to support the educator-patient relationship. Health professionals who may be unaware of their patient's social context and current asthma practices could possibly contribute to the less desirable outcome of ongoing symptoms and increasing complex treatment regimens [32-34].

By using this PCE method, clinical guidelines can be conveyed using a learner-centred process resulting in positive outcomes for patients, with both their and the health professionals' needs being met. The current authors believe that the PCE process goes part way to addressing a number of the patient education issues facing health professionals, such as the diverse perspectives of patients and health professionals and the difficulty health professionals face in translating clinical guidelines to patients [35-37]. Some ED studies of patients with acute asthma have focused on improving primary care follow-up through telephone reminders [15] and primary care-based education [16], which have shown very little or no improvement in patient behaviour or asthma outcomes. Furthermore, a disproportionately high number of patients who do not have regular contact with their GP are admitted to hospital after seeking emergency care [38]. The PCE education method and its timing have the potential to benefit this particular patient group, as the findings of the present study suggest that patients in the PCE group without prior GP care had fewer re-attendances. Whether patients re-engaged with the primary physician rather than relying on secondary care is still yet to be ascertained.

Participants randomised to PCE group were asked what the most important issue was for them at that moment, and were advised to alert the educator to events/beliefs or concerns and fears that were affecting them $[39,40]$. The action of acknowledging the patient's concerns indicates that the health professional is concerned about them as an individual [40, 41]. The current authors suggest that this action may encourage patients to be active participants, rather than taking a passive role while they deal internally with other issues. The PCE group was also asked what the most important asthma issue was for them, and themes from participants' responses reflect the past Australian National Asthma Council's campaigns. The present authors believe that the themes from the patient responses will reassure health professionals and organisations, such as the Australian National Asthma Council, that their campaigns are targeting appropriate asthma issues that are of concern to patients.

The results of the present study indicate that when patients are given a list of topics and the autonomy to choose the order in which they are to be delivered during the education process, they differed significantly in their choice from the standard format in current use. The PCE approach acknowledges that different patients with asthma may need specific information related to certain topics at different times in their life [42]. The change in prioritisation of topics between phase 1 and phase 2 
further supports this premise. A standard curriculum delivered by means of a patient-centred approach to asthma education, using learner-centred elements, may go part way towards addressing these issues and provide a sustainable approach to asthma education in the ED.

The present study suggests that a learner-centred approach to asthma education may be useful in reducing re-attendances to the emergency department and, therefore, has important implications for the way health professionals educate patients. The uncomplicated, brief, patient-centred education process using a basic chronic disease guideline curriculum may be of value, particularly for people who are treated, educated and discharged from the emergency department. The patientcentred education approach needs further study and extension to confirm and generalise the results.

\section{ACKNOWLEDGEMENTS}

The authors are grateful to R. Ruffin (University of Adelaide, Adelaide, Australia), P. Glasziou (University of Oxford, Oxford, UK) and M. Fleming (Queensland University of Technology, Brisbane, Australia) for helpful comments during preparation of this manuscript, and to R. Perera (University of Oxford, Oxford, UK) for statistical advice.

\section{REFERENCES}

1 Australian Centre for Asthma Monitoring. Asthma in Australia 2005. Asthma series no. 2. Australian Institute of Health and Welfare cat. no. ACM 6; 2005.

2 Global Initiative for Asthma. Global Strategy for Asthma Management and Prevention. 2006. www.ginasthma.org Date last accessed: June 19, 2007. Date last updated: December 2007.

3 Cowie RL, Underwood MF, Revitt SG, Field SK. Predicting emergency department utilization in adults with asthma: a cohort study. J Asthma 2001; 38: 179-184.

4 Marks GB, Heslop W, Yates DH. Prehospital management of exacerbations of asthma: relation to patient and disease characteristics. Respirology 2000; 5: 45-50.

5 Kwong T, Town I, Holst PE, Beasley R. A study of the management of asthma in a hospital emergency department. N Z Med J 1989; 102: 547-549.

6 Emerman CL. Relapse following treatment of acute asthma in the emergency department. J Asthma 2000; 37: 701-708.

7 Ducharme FM, Kramer MS. Relapse following emergency treatment for acute asthma: can it be predicted or prevented? J Clin Epidemiol 1993; 46: 1395-1402.

8 Chidley KE, Wood-Baker R, Town GI, Sleet RA, Holgate ST. Reassessment of asthma management in an accident and emergency department. Respir Med 1991; 85: 373-377.

9 Dales RE, Schweitzer I, Kerr P, Gougeon L, Rivington R, Draper J. Risk factors for recurrent emergency department visits for asthma. Thorax 1995; 50: 520-524.

10 Emerman CL, Cydulka RK. Factors associated with relapse after emergency department treatment for acute asthma. Ann Emerg Med 1995; 26: 6-11.

11 Gibson PG, Talbot PI, Hancock J, Hensley MJ. A prospective audit of asthma management following emergency asthma treatment at a teaching hospital. Med J Aust 1993; 158: 775-778.
12 Milks CJ, Oppenheimer JJ, Bielory L. Comparison of emergency room asthma care to National Guidelines. Ann Allergy Asthma Immunol 1999; 83: 208-211.

13 Reid J, Marciniuk DD, Cockcroft DW. Asthma management in the emergency department. Can Respir J 2000; 7: 255-260.

14 Munro J, Richardson M, O'Connell J, Hawley R. Current practice in the emergency department: documenting asthma management. Respirology 2002; 7: Suppl. 1, A1.

15 Baren JM, Boudreaux ED, Brenner BE, et al. Randomized controlled trial of emergency department interventions to improve primary care follow-up for patient with acute asthma. Chest 2006; 129: 257-265.

16 Griffiths C, Foster G, Barnes N, et al. Specialist nurse intervention to reduce unscheduled asthma care in a deprived multiethnic area: the east London randomised controlled trial for high risk asthma (ELECTRA). BMJ 2004; 328: 144.

17 National Institutes of Health, Global Initiative for Asthma, National Heart, Lung, and Blood Institute. Asthma management and prevention: a practical guide for public health officials and health care professionals. Publication no. 95-3659; 2005.

18 British Thoracic Society, Scottish Intercollegiate Guidelines Network. British Guideline on the Management of Asthma. 2005.

19 Smith S, Mitchell C, Bowler S. Patient-centered education: applying learner-centered concepts to asthma education. J Asthma 2007; 44: 799-804.

20 Assor A, Kaplan H, Roth G. Choice is good, but relevance is excellent: autonomy-enhancing and suppressing teacher behaviours predicting students' engagement in schoolwork. Br J Educ Psychol 2002; 72: 261-278.

21 Mead N, Bower P. Patient-centredness: a conceptual framework and review of the empirical literature. Soc Sci Med 2000; 51: 1087-1110.

22 Yoon R, McKenzie DK, Bauman A, Miles DA. Controlled trial evaluation of an asthma education programme for adults. Thorax 1993; 48: 1110-1116.

23 Abdulwadud O, Abramson M, Forbes A, James A, Walters EH. Evaluation of a randomised controlled trial of adult asthma education in a hospital setting. Thorax 1999; 54: 493-500.

24 National Asthma Council Australia. Asthma Management Handbook 2002. Melbourne, National Asthma Council Australia Ltd, 2002.

25 Deci EL. Self-determination theory: an approach to human motivation and personality. http://psych.rochester.edu/ SDT/ Date last accessed: June 19, 2007. Date last updated: November 4, 2007.

26 Juniper EF, O’Byrne PM, Guyatt GH, Ferrie PJ, King DR. Development and validation of a questionnaire to measure asthma control. Eur Respir J 1999; 14: 902-907.

27 Kolbe J, Fergusson W, Vamos M, Garrett J. Case-control study of severe life threatening asthma (SLTA) in adults: psychological factors. Thorax 2002; 57: 317-322.

28 Baren JM, Shofer FS, Ivey B, et al. A randomized, controlled trial of a simple emergency department intervention to improve the rate of primary care follow-up for patients with acute asthma exacerbations. Ann Emerg Med 2001; 38: 115-122. 
29 McClellan VE, Garrett JE. Attendance failure at Middlemore Hospital asthma clinic. N Z Med J 1989; 102: 211-213.

30 Abdulwadud O, Abramson M, Forbes A, et al. Attendance at an asthma educational intervention: characteristics of participants and non-participants. Respir Med 1997; 91: 524-529.

31 Gibson PG, Powell H, Coughlan J, et al. Limited (information only) patient education programs for adults with asthma. Cochrane Database Syst Rev 2002; 2: CD001005.

32 Little P, Everitt H, Williamson I, et al. Preferences of patients for patient centred approach to consultation in primary care: observational study. BMJ 2001; 322: 468-472.

33 Little P, Everitt H, Williamson I, et al. Observational study of effect of patient centredness and positive approach on outcomes of general practice consultations. BMJ 2001; 323: 908-911.

34 Abramson MJ, Bailey MJ, Forbes AB, Walters EH, Victorian Asthma Mortality Study Group. How well do doctors know their patients with severe asthma? Intern Med J 2003; 33: 557-565.

35 Sawyer SM, Fardy HJ. Bridging the gap between doctors' and patients' expectations of asthma management. J Asthma 2003; 40: 131-138.
36 Goeman DP, Hogan CD, Aroni RA, et al. Barriers to delivering asthma care: a qualitative study of general practitioners. Med J Aust 2005; 183: 457-460.

37 Epstein RM, Alper BS, Quill TE. Communicating evidence for participatory decision making. JAMA 2004; 291: 2359-2366.

38 Adams RJ, Smith BJ, Ruffin RE. Factors associated with hospital admissions and repeat emergency department visits for adults with asthma. Thorax 2000; 55: 566-573.

39 Arborelius E, Bremberg S. Prevention in practice. How do general practitioners discuss life-style issues with their patients? Patient Educ Couns 1994; 23: 23-31.

40 Arborelius E, Osterberg E. How do GPs discuss subjects other than illness? Formulating and evaluating a theoretical model to explain successful and less successful approaches to discussing psychosocial issues. Patient Educ Couns 1995; 25: 257-268.

41 Suhonen R, Välimäki M, Leino-Kilpi H. "Individualised care" from patients', nurses' and relatives' perspective-a review of the literature. Int J Nurs Stud 2002; 39: 645-654.

42 Michie S, Miles J, Weinman J. Patient-centredness in chronic illness: what is it and does it matter? Patient Educ Couns 2003; 51: 197-206. 